\title{
AÇÃO DE FUNGICIDAS UTILIZADOS NA CULTURA DO PEPINO SOBRE LARVAS DE PRIMEIRO ÍNSTAR DE CHRYSOPERLA EXTERNA (HAGEN, 1861) (NEUROPTERA: CHRYSOPIDAE) E OS EFEITOS SOBRE SUAS FASES SUBSEQÜENTES
}

\section{R.R. Dacosta, G.A. Carvalho, C.F. Carvalho, R.R. Costa}

Universidade Federal de Lavras, Departamento de Entomologia, CP 3037, CEP 37200-000, Lavras, MG, Brasil. E-mail:ronelzagro@yahoo.com.br

\section{RESUMO}

Objetivou-se avaliar a toxicidade de alguns fungicidas aplicados em cultura de pepino (Cucumis satious L.), em função das formas de exposição, por contato ou ingestão de presas contaminadas, para larvas de primeiro ínstar de Chrysoperla externa (Hagen) alimentadas com Aphis gossypii Glover (Hemiptera: Aphididae) e os efeitos sobre as fases subseqüentes de desenvolvimento do predador. Os experimentos foram conduzidos em condições controladas a $25 \pm 2{ }^{\circ} \mathrm{C}, 70 \pm 10 \%$ UR e fotofase de 12 horas. O delineamento experimental foi inteiramente ao acaso, com quatro tratamentos e seis repetições, sendo cada parcela composta por quatro larvas. Os compostos utilizados e suas respectivas dosagens de aplicação em g i.a. $L^{-1}$ foram: enxofre (Kumulus 800PM - 1,6), mancozebe (Manzate 800PM - 1,6) e oxicloreto de cobre (Recop 840PM - 1,49). A testemunha foi composta por água destilada. No bioensaio de contato, larvas de primeiro ínstar de C. externa receberam os produtos via pulverização, por meio de torre de Potter e, em seguida, foram individualizadas em tubos de vidro, as quais foram alimentadas diariamente com ninfas de $A$. gossypii. No bioensaio via ingestão, as ninfas de $A$. gossypii tratadas via pulverização com os compostos foram oferecidas como alimento para larvas de primeiro estádio de C. externa. O efeito total dos fungicidas para C. externa foi estabelecido conforme as classes de toxicidade preconizadas pela IOBC, em que oxicloreto de cobre mostrou-se inócuo (classe 1) via contato ou ingestão. Enxofre e mancozebe por ingestão foram inócuos, e quando aplicados via contato foram levemente nocivos (classe 2).

PALAVRAS-CHAVE: Cucurbitaceae, produto fitossanitário, afídeo, crisopídeo.

\section{ABSTRACT}

ACTION OF FUNGICIDES USED IN CUCUMBER CROP ON FIRST-INSTAR LARVAE OF CHRYSOPERLA EXTERNA (HAGEN, 1861)(NEUROPTERA:CHRYSOPIDAE) ANDTHE EFFECTS ON THEIR SUBSEQUENT STAGES. This study was aimed to evaluate the toxicity of some fungicides applied on cucumber crop (Cucumis sativus L.) in function in the manner of exposure, by contact or ingestion of contaminated preys, for first-instar Chrysoperla externa (Hagen) larvae fed with Aphis gossypii Glover (Hemiptera: Aphididae), and the effects on the subsequent stages of the predator. The experiments were conducted under controlled conditions at $25 \pm 2{ }^{\circ} \mathrm{C}$; $\mathrm{RH}$ : 70 $\pm 10 \%$ and $12 \mathrm{~h}$ of photophase. The experimental design was completely randomized with 4 treatments and 6 replicates, each plot made up of 4 larvae. The compounds utilized and their respective dosages of application in $\mathrm{g}$ a.i. $\mathrm{L}^{-1}$ were sulfur (Kumulus $800 \mathrm{PM}-1.6$ ), mancozeb (Manzate 800PM - 1.6) and copper oxichloride (Recop 840PM - 1.49). The control consisted of distilled water. First-instar larvae received the chemicals via spraying and were then individualized into glass tubes, and fed A. gossypii nymphs. In the bioassay, via ingestion, the A. gossypii nymphs treated via spraying with the compounds were given as food to first-stage larvae of $C$. externa. The total effect of the fungicides from C. externa was established according to the toxicity classes of the IOBC scale, where copper oxichloride proved harmless (class 1) via contact or ingestion. Sulfur and mancozeb by ingestion were harmless, and slightly harmful (class 2) when applied via contact.

KEY WORDS: Cucurbitaceae, pesticide, aphid, green lacewing. 


\section{INTRODUÇÃO}

As doenças fúngicas são importantes na cultura do pepino (Cucumis satious L.), principalmente quando cultivado em ambiente protegido, visto que essa cultura é suscetível ao ataque deinúmeros patógenos, oque torna necessário para seu controle o uso de produtos fitossanitários (JULIATII, 2001). Outro problema fitossanitário éo inseto-praga Aphis gossypii Glover, 1877 (Hemiptera: Aphididae) que, além de ser vetor do vírus do mosaico-do-pepino (CMV) (ÁvILA, 1982), provoca danos às plantas pela sucção de seiva e pela secreção do "honeydew", favorecendo a proliferação de fungos conhecidos comumente como "fumagina" (MATTHEWS; TunStall, 1994; Degrande, 1998; Bueno, 2005).

O manejo desses pulgões pode ser realizado por meio da utilização de crisopídeos, insetos pertencentes à família Chrysopidae e que apresentam importante atuaçãonoequilíbrio da densidade populacional de muitos artrópodes-praga. A espécie Chrysoperla externa (Hagen, 1861) (Neuroptera: Chrysopidae) destaca-sena Região Neotropical, ocorrendo naturalmente em inúmeras culturas de interesse econômico (FonsECA et al., 2001). Esse crisopídeo apresenta fácil adaptação e ampla distribuição em diversos agroecossistemas, alta capacidade predatória e facilidade de localização de presas (BERTI FILHo et al., 2000; Costa et al., 2002).

A espécie C. externa é predadora na fase de larva e a suscetibilidade dessa fase aos diferentes produtos fitossanitários varia em função da classe do produtoe, também, do grupo químico (FreitAs; FernANDES, 1996).

Assim, considerando o potencial e a importância de C. externa para o controle biológico de artrópodespraga em agroecossistemas, objetivou-se estudar os efeitos de fungicidas recomendados para a cultura do pepinosobrelarvas deprimeiroínstardessecrisopídeo e a influência sobre as fases subseqüentes do desenvolvimento do predador.

\section{MATERIALEMÉTODOS}

Sementes de pepino (C. sativus) cultivar Caipira foram semeadas em vasos de polietileno com capacidade para $2 \mathrm{~L}$, contendo como substrato mistura de terra de barranco e esterco de curral (3:1) e mantidos em casa-de-vegetação. As plantas receberam adubaçãonitrogenada com $1,25 \mathrm{~g}$ de sulfato de amônia após 15 dias da germinação.

A criação do pulgão A. gossypi teve início a partir de fêmeas adultas oriundas da criação de manutenção de laboratório, as quais foram transferidas para as plantas de pepino com 20 dias de idade. Os vasos contendo as plantas foram mantidos em 4 gaiolas de madeira com $1,2 \mathrm{~m}$ decomprimento, $70 \mathrm{~cm}$ delargura e $90 \mathrm{~cm}$ de altura, revestidas com tecido "voil", na proporção de 20 vasos por gaiola.

Foram avaliados fungicidas protetores registrados para a cultura de pepino, testados nas maiores concentrações recomendadas pelos fabricantes. Os produtos, com seus respectivos nomes comerciais, técnicos e dosagens em g i.a. $\mathrm{L}^{-1}$ foram: Kumulus $800 \mathrm{PM}$ enxofre $(1,6)$; Manzate 800 PM - mancozebe $(1,6)$ e Recop 840 PM - oxicloreto de cobre $(1,5)$.

Efeito dos fungicidas sobre larvas de primeiro ínstar, e efeitos sobre os demais estádios e/ou estágios subseqüentes, oriundos de larvas de primeiro ínstar contaminadas por meio de contato ou ingestão

Empregaram-se 24 larvas de primeiro ínstar de $C$. externa com cerca de 12 horas deidade, por tratamento.

Para avaliar o efeito de contato dos produtos, essas larvas foram colocadas em placas dePetri de $15 \mathrm{~cm}$ de diâmetro e receberam os compostos por meio de pulverização em torre de Potter regulada à pressão de 15 lb.pol-2 ${ }^{-2}$ com taxa de aplicação de $1,5 \pm 0,5 \mu$ g de calda $\mathrm{cm}^{-2}$, conforme recomendação da IOBC (DEGRANDE et al., 2002). Em seguida, foram individualizadas em tubos de vidro de $2,5 \mathrm{~cm}$ de diâmetro por $8,5 \mathrm{~cm}$ de altura, vedados com filme de PVC e alimentadas, diariamente, ad libitum com ninfas de terceiro e quarto ínstares de $A$. gossypii, isentas de fungicidas.

Noteste deingestão, plantas de pepino com 20 dias deidade, contendo os afídeos, receberam as aplicações dos fungicidas (enxofre, mancozebe e oxicloreto de cobre) eágua destilada (testemunha), a cada sete dias, por meio de pulverizador manual até o ponto de escorrimentoda calda, com volumemédiodeaplicação de 7,5 mL por planta. Uma hora após, os afídeos contaminados foram oferecidos ad libitum para larvas deprimeiroínstardeC.externa previamenteindividualizadas em tubos de vidro em laboratório.

O delineamento experimental utilizado foi o inteiramentecasualizado, com quatrotratamentoseseisrepetições, sendo cada parcela composta por quatro larvas de primeiro ínstar, tanto para o bioensaio de contato como para ingestão. Foram avaliadas a duração em dias e a sobrevivência(\%)delarvasdeprimeiro,segundoeterceiro ínstares e das pupas; avaliando-se, também, a razão sexual e sobrevivência de adultos 24 horas após a emergência, oriundos das larvas de primeiro ínstar de $C$. externa, em função de fungicidas e das formas deexposição, via contato ou ingestão, em esquema fatorial $(4 \times 2)$.

Efeito dos fungicidas na fecundidade de $C$. externa oriundos de larvas de primeiro ínstar contaminadas via contato ou ingestão

Após a emergência, crisopídeos foram separados pelosexo emantidosnaproporçãodeumcasal porgaiola 
dePVC de $10 \mathrm{~cm}$ dealturae $10 \mathrm{~cm}$ dediâmetro, revestida internamentecom papel-filtroe tendoas partes superior e inferior fechadas com tecido tipo "voil". As gaiolas foram apoiadas em bandejas de alumínio de $50 \mathrm{~cm}$ de comprimento e $30 \mathrm{~cm}$ de largura e mantidas em salas climatizadas a $25 \pm 2{ }^{\circ} \mathrm{C}, 70 \pm 10 \%$ UR e fotofase de 12 horas. Como alimento, foi oferecida uma dieta à base de lêvedodecerveja emel,na proporçãovolumétrica de1:1, pinceladaem pedaçodematerial poroso(esponja)fixado na extremidade de tubos de vidro com capacidade para $8 \mathrm{~mL}$ contendoágua destilada, os quais foram dispostos na parte superior de cada gaiola. O delineamento experimental utilizado foi inteiramente casualizado, com seis repetições para cada tratamento, sendo cada parcela representadaporumcasaldeC.externa.Avaliou-senesse ensaio, em intervalos regulares de três dias, durante seis semanasconsecutivas, onúmerodeovos por fêmeaesua viabilidade, coletando-se aleatoriamente 96 ovos dentro decada tratamento, os quais foramindividualizados em compartimentos de placas de microtitulação usadas em teste ELISA (Enzime Linked Immunosorbent Assay) e mantidos duranteseis diasnasmesmascondições climáticas dos adultos para eclosão das larvas.

\section{Determinação do efeito total de cada fungicida}

Oefeito total (E\%) decada fungicida foi determinado em função da redução da porcentagem de mortalidade e fecundidade, sendo calculada pela equação proposta por VOGT (1992), descrita a seguir:

$\mathrm{E}=100 \%-(100 \%-\mathrm{M} \%) \times \mathrm{R} 1 \times \mathrm{R} 2$

emque:

$\mathrm{E}=$ efeito total $(\%)$;

$\mathrm{M} \%$ = mortalidade no tratamento corrigida pela fórmula de Аввотт (1925);

R1 = razão entre a média diária de ovos colocados por fêmea tratada e não tratada;

$\mathrm{R} 2$ = razão entre a viabilidade média de ovos postos por fêmea tratada e não tratada.

Após a obtenção do efeito total, cada fungicida foi enquadrado em uma das quatro classes de toxicidade propostas pela IOBC (HASSAN, 1997; STERK et al.,1999): classe 1 = inócuo $(\mathrm{E}<30 \%)$; classe 2 = levemente nocivo (30 $\leq \mathrm{E}<79 \%$ ); classe 3 = moderadamente nocivo $(80 \leq \mathrm{E} \leq 99 \%)$ e classe $4=$ nocivo $(\mathrm{E}>99 \%)$.

\section{Análise estatística}

Para os dados referentes à duraçãoe sobrevivência ao longo do período de larva e pupa, razão sexual e sobrevivência deadultos oriundos delarvas deprimeiro ínstar tratados, utilizou-se um esquema fatorial de produtos $x$ forma deexposição $(4 \times 2)$, foram analisados pelo programa estatístico Sisvar (FERREIRA, 2000).

Nas duas análises, para as variáveis dependentes, em que o teste F da ANAVA (BANZATTO; KRONKA, 1989) foi significativo $(\mathrm{P}<0,05)$, empregou-se o teste de Scott-Knott para comparação das médias dos dados qualitativos a 5\% de significância. Em se tratando da análise donúmeroe da viabilidadedeovos aolongodo tempo, utilizaram-se os modelos de regressão, dentre osquais avaliaram-seosmodelos linearesequadráticos por meio do procedimento REG do SAS (SAS,1990).

\section{RESULTADOSEDISCUSSÃO}

Efeito dos fungicidas sobre larvas de primeiro ínstar, e efeitos sobre os demais estádios e/ou estágios subseqüentes, oriundos de larvas de primeiro ínstar contaminadas por meio de contato ou ingestão

Para a duração em dias do primeiro ínstar de $C$. externa não foi observada interação entre os fungicidas e as formas de exposição, contato ou ingestão (Tabela $1)$. Esses resultados foram semelhantes aos observados por Silva et al. (2005) em larvas de primeiro ínstar de C. externa tratadas via contato com oxicloreto de cobre sendo as larvas alimentadas com ovos de Anagasta kuehniella (Zeller, 1879) (Lepidoptera: Pyralidae), e ao trabalho básico de biologia para larvas de primeiroínstar alimentadas com ovos desse mesmolepidóptero. Dessa forma, os fungicidas enxofre, mancozebe exicloreto de cobre não interferiram na duração do primeiroínstar desse crisopídeo, independente da forma de exposição.

Tabela 1 - Duração média (dias) ( \pm EP) do primeiro ínstar de C. externa de larvas tratadas com os fungicidas via contato ou ingestão. Temp.: $25 \pm 2{ }^{\circ} \mathrm{C}$; UR: $70 \pm 10 \%$ e fotofase: $12 \mathrm{~h}$.

\begin{tabular}{llll}
\hline Tratamento & \multicolumn{2}{c}{ Forma de exposição } & Média \\
\cline { 2 - 4 } & Contato & Ingestão & $3,7 \pm 0,10 \mathrm{a}$ \\
\hline Testemunha & $4,0 \pm 0,14$ & $3,5 \pm 0,14$ & $3,7 \pm 0,12 \mathrm{a}$ \\
Enxofre & $4,0 \pm 0,12$ & $3,9 \pm 0,10$ & $3,8 \pm 0,11 \mathrm{a}$ \\
Mancozebe & $4,0 \pm 0,13$ & $3,7 \pm 013$ & $3,8 \pm 0,10 \mathrm{a}$ \\
Oxicloreto de cobre & $3,8 \pm 0,14$ & $3,8 \pm 0,14$ & \\
\hline CV $(9,1 \%)$ & $3,95 \pm 0,07 \mathrm{~A}$ & $3,72 \pm 0,08 \mathrm{~A}$ &
\end{tabular}

A análise de variância não indicou diferença entre as médias ( $\mathrm{P}>0,05)$. 
Para a sobrevivência das larvas de primeiroínstar, ocorreram diferenças significativas na interação dos fatores fungicidas e forma de exposição, sendo verificada média geral de $81,7 \%$ de sobrevivência nos tratamentos com fungicidas, com uma queda de 1,2 vezes comparadas à testemunha. Nas duas formas de exposição pelos fungicidas, as porcentagens de sobrevivência foram semelhantes, com média de 85,8\% (Tabela 2). Silva et al. (2005) verificaram uma sobrevivência de $87,5 \%$ para larvas de primeiro ínstar tratadas via contato com oxicloreto de cobre, sendo as larvas alimentadas com ovos de A. kuehniella.

Tabela 2 - Sobrevivência média (\%) do primeiro ínstar de C. externa de larvas tratadas com os fungicidas via contato ou ingestão. Temp.: $25 \pm 2^{\circ} \mathrm{C}$; UR: $70 \pm 10 \%$ e fotofase: $12 \mathrm{~h}$.

\begin{tabular}{|c|c|c|}
\hline \multirow[t]{2}{*}{ Tratamento } & \multicolumn{2}{|c|}{ Forma de aplicação } \\
\hline & Contato & Ingestão \\
\hline Testemunha & $100,0 \pm 4,85$ a $\mathrm{A}$ & $95,8 \pm 4,85$ a $A$ \\
\hline Enxofre & $75,0 \pm 4,83 \mathrm{~b} \mathrm{~B}$ & $90,3 \pm 4,85$ a $\mathrm{A}$ \\
\hline Mancozebe & $83,3 \pm 4,84 \mathrm{~b} \mathrm{~A}$ & $79,2 \pm 4,85 \mathrm{~b} \mathrm{~A}$ \\
\hline Oxicloreto de cobre & $95,8 \pm 4,85$ a $\mathrm{A}$ & $66,7 \pm 4,85 \mathrm{~b} \mathrm{~B}$ \\
\hline CV $(13,9 \%)$ & $88,5 \pm 4,84 \mathrm{~A}$ & $83,0 \pm 4,85 \mathrm{~A}$ \\
\hline
\end{tabular}

Médias seguidas pela mesma letra maiúscula na linha e minúscula, na coluna não diferem estatisticamente entre si pelo teste de F e de Scott e Knott, respectivamente $(\mathrm{P}>0,05)$.

Na duração média do segundoínstar de C.externa provenientes de larvas de primeiro ínstar, tratadas com os fungicidas via contato ou ingestão, observouse diferenças nas formas de exposição e na interação entre os produtos. As maiores médias foram observadas quando as larvas foram tratadas via contato, 4,0 dias de duração, e para as tratadas via ingestão a média foi 3,4 dias. Na forma de exposição via contato, não houve diferença significativa entre os fungicidas, mas via ingestão de pulgões contaminados todos os fungicidas diferiram da testemunha (Tabela 3).

Utilizando A. gossypii como fonte alimentar de larvas dessa mesma espécie de crisopídeo, foram encontradas algumas diferenças em resultados obtidos de estudos básicos de biologia desse predador. SANTOS et al. (2003) alimentando larvas de segundo ínstar de C. externa com esse pulgão, criado em diferentes cultivares de algodoeiro elevando em consideração a influência dos tricomas foliares, observaram duração média de 2,9 dias. Costa et al. (2002) constataram que esse mesmo alimento proporcionou duração média, em larvas de segundo ínstar, de 2,5 dias. Já os resultados de PESSOA et al. (2004) aproximaramse das médias observadas nesse trabalho para o efeito deingestão, com variação de 3,25a 3,5 dias, o que pode auxiliar na confirmação da inocuidade dos fungicidas testados a esse predador.

Tabela 3 - Duração média (dias) ( \pm EP) do segundo ínstar de C. externa provenientes de larvas de primeiro ínstar tratadas com os fungicidas via contato ou ingestão. Temp.: $25 \pm 2{ }^{\circ} \mathrm{C}$; UR: $70 \pm 10 \%$ e fotofase: $12 \mathrm{~h}$.

\begin{tabular}{|c|c|c|}
\hline \multirow[t]{2}{*}{ Tratamento } & \multicolumn{2}{|c|}{ Forma de exposição } \\
\hline & Contato & Ingestão \\
\hline Testemunha & $4,0 \pm 0,12$ a $A$ & $3,9 \pm 0,12$ a A \\
\hline Enxofre & $3,9 \pm 0,11$ a $A$ & $3,1 \pm 0,11 b$ B \\
\hline Mancozebe & $4,0 \pm 0,13$ a $A$ & $3,3 \pm 0,13 b$ B \\
\hline Oxicloreto de cobre & $4,0 \pm 0,12$ a $\mathrm{A}$ & $3,4 \pm 0,10 \mathrm{~b} \mathrm{~B}$ \\
\hline CV $(8,1 \%)$ & $4,0 \pm 0,12 \mathrm{~A}$ & $3,4 \pm 0,10 \mathrm{~B}$ \\
\hline
\end{tabular}

Médias seguidas pela mesma letra maiúscula, na linha, e minúscula, na coluna não, diferem estatisticamente entre si pelo teste de F e de Scott e Knott, respectivamente $(\mathrm{P}>0,05)$.

Quanto à sobrevivência das larvas de segundo ínstar de C. externa, não foram observadas diferenças significativas, com médias de $94,4 \%$ de sobrevivência via contato e $94,0 \%$ de sobrevivência via ingestão (Tabela 4).

Tabela 4 - Sobrevivência média (\%) de larvas de segundo ínstar de C. externa, provenientes de larvas de primeiro ínstar tratadas com os fungicidas via contato ou ingestão. Temp.: $25 \pm 2{ }^{\circ} \mathrm{C}$; UR: $70 \pm 10 \%$ e fotofase: $12 \mathrm{~h}$.

\begin{tabular}{lcc}
\hline Tratamento & \multicolumn{2}{c}{ Forma de exposição } \\
\cline { 2 - 3 } & \multicolumn{1}{c}{ Contato } & Ingestão \\
\hline Testemunha & $95,8 \pm 4,16$ & $91,7 \pm 4,17$ \\
Enxofre & $95,8 \pm 4,17$ & $95,8 \pm 4,13$ \\
Mancozebe & $90,3 \pm 4,16$ & $95,8 \pm 4,15$ \\
Oxicloreto de cobre & $95,8 \pm 4,17$ & $91,7 \pm 4,17$ \\
\hline CV $(12,4 \%)$ & $94,4 \pm 4,17$ & $94,0 \pm 4,15$
\end{tabular}

A análise de variância não indicou diferença entre as médias $(\mathrm{P}>0,05)$.

Por meio dos dados de duração do terceiroínstar, oriundas das larvas de primeiro ínstar tratadas, pode-se verificar que as formas de exposição aos produtos diferiram, sendo constatados 3,2 dias via contato e 2,8 dias via ingestão, e entre os tratamentos não houve diferença significativa (Tabela 5). Esses resultados assemelham-se aos de SiLVA et al. (2005) 
que não observaram influência do enxofre e do oxicloreto de cobre, via contato, na duração de larvas de terceiro ínstar provenientes delarvas de primeiro ínstar tratadas.

Tabela 5 - Duração média (dias) ( \pm EP) do terceiro ínstar de C. externa provenientes de larvas de primeiro ínstar tratadas com os fungicidas via contato ou ingestão. Temp.: $25 \pm 2{ }^{\circ} \mathrm{C}$; UR: $70 \pm 10 \%$ e fotofase: $12 \mathrm{~h}$.

\begin{tabular}{lcc}
\hline Tratamento & \multicolumn{2}{c}{ Forma de exposição } \\
\cline { 2 - 3 } & \multicolumn{1}{c}{ Contato } & Ingestão \\
\hline Testemunha & $3,0 \pm 0,14$ a A & $2,5 \pm 0,14$ a B \\
Enxofre & $3,3 \pm 0,13$ a A & $2,9 \pm 0,12$ a B \\
Mancozebe & $3,3 \pm 0,12$ a A & $2,9 \pm 0,11$ a B \\
Oxicloreto de cobre & $3,0 \pm 0,11$ a A & $2,7 \pm 0,14$ a B \\
\hline CV $(11,5 \%)$ & $3,2 \pm 0,11$ A & $2,8 \pm 0,13$ B \\
\hline
\end{tabular}

Médias seguidas pela mesma letra maiúscula, na linha, e minúscula, na coluna, não diferem estatisticamente entre si pelo teste de F e de Scott e Knott, respectivamente $(\mathrm{P}>0,05)$.

Para a sobrevivência (\%) de larvas de terceiro ínstar, observou-se que não ocorreram diferenças significativas entre os tratamentos bem comona forma de exposição dos produtos, com média de $94,8 \%$ de sobrevivência. Esses resultados se assemelham aos verificados porSiLva et al. (2005) que, ao pulverizarem larvas de primeiro ínstar com oxicloreto de cobre e enxofre, observaram que não ocorreram diferenças significativas entre as porcentagens de sobrevivência doterceiroínstar, eporSANTOSetal. (2003) queverificaram que larvas de terceiro ínstar de C. externa alimentadas com A. gossypii apresentaram 97,3\% de sobrevivência.

A duração da fase de pupa de C. externa, provenientes de larvas de primeiro ínstar tratadas, apresentou diferenças apenas na forma de exposição dos fungicidas, sendo a maior duração observada quando os insetos entraram em exposição aos fungicidas via ingestão, com média de 11,8 dias de duração (Tabela 6). Para a sobrevivência das pupas, houve variação para as formas de exposição dos fungicidas, sendo as médias de $81,3 \%$ e $95,8 \%$ de sobrevivência via contato e ingestão, respectivamente (Tabela 7). Os resultados obtidos por SILVA et al. (2005) para enxofre e oxicloreto de cobre, aplicados em larvas de primeiro estádio, não afetaram a fase de pupa dos insetos, não diferindo da testemunha, e a duração foi de 10,1 dias, com sobrevivência de $97,5 \%$ a $100 \%$.
Tabela 6 - Duração média (dias) $( \pm \mathrm{EP})$ da fase de pupa de C. externa provenientes de larvas de primeiro ínstar tratadas com os fungicidas via contato ou ingestão. Temp.: $25 \pm 2{ }^{\circ}$ C; UR: $70 \pm 10 \%$ e fotofase: $12 \mathrm{~h}$.

\begin{tabular}{|c|c|c|}
\hline \multirow[t]{2}{*}{ Tratamento } & \multicolumn{2}{|c|}{ Forma de exposição } \\
\hline & Contato & Ingestão \\
\hline Testemunha & $11,0 \pm 0,16$ a $B$ & $11,7 \pm 0,16$ a $A$ \\
\hline Enxofre & $11,2 \pm 0,15$ a B & $11,7 \pm 0,14$ a $\mathrm{A}$ \\
\hline Mancozebe & $11,1 \pm 0,14$ a B & $11,7 \pm 0,16$ a $A$ \\
\hline Oxicloreto de cobre & $10,9 \pm 0,16$ a B & $12,1 \pm 0,15$ a $\mathrm{A}$ \\
\hline CV $(3,4 \%)$ & $11,0 \pm 0,15 \mathrm{~B}$ & $11,8 \pm 0,15 \mathrm{~A}$ \\
\hline
\end{tabular}

Médias seguidas pela mesma letra maiúscula, na linha, e minúscula, na coluna, não diferem estatisticamente entre si pelo teste de F e de Scott e Knott, respectivamente $(\mathrm{P}>0,05)$.

Tabela 7 - Sobrevivência média (\%) da fase de pupa de $C$. externa, provenientes de larvas de primeiro ínstar tratadas com os fungicidas via contato ou ingestão. Temp.: 25 $\pm 2{ }^{\circ} \mathrm{C}$; UR: $70 \pm 10 \%$ e fotofase: $12 \mathrm{~h}$.

\begin{tabular}{lcr}
\hline Tratamento & \multicolumn{2}{c}{ Forma de exposição } \\
\cline { 2 - 3 } & \multicolumn{1}{c}{ Contato } & \multicolumn{1}{c}{ Ingestão } \\
\hline Testemunha & $91,7 \pm 4,56$ a A & $95,8 \pm 4,53$ a A \\
Enxofre & $79,2 \pm 4,52$ a B & $95,8 \pm 4,40$ a A \\
Mancozebe & $66,7 \pm 4,56$ b B & $100,0 \pm 4,56$ a A \\
Oxicloreto de cobre & $87,5 \pm 4,53$ a A & $91,7 \pm 4,32$ a A \\
\hline CV (12,6\%) & $81,3 \pm 4,54$ B & $95,8 \pm 4,32$ A \\
\hline
\end{tabular}

Médias seguidas pela mesma letra maiúscula, na linha, e minúscula, na coluna, não diferem estatisticamente entre si pelo teste de F e de Scott e Knott, respectivamente $(\mathrm{P}>0,05)$.

Para adultos de C. externa, a sobrevivência 24 horas após a emergência não foi significativamente diferentepara os tratamentos testados quantoà forma de exposição e à interação entre os fatores. As médias obtidas quanto às formas de aplicação foram 90,3 e $86,1 \%$ de sobrevivência, via contato e ingestão, respectivamente (Tabela 8 ).

A forma de exposição dos insetos aos fungicidas e a interação dos fatores não influenciaram na razão sexual dos insetos, com valor médio de 0,5 via contato e 0,5 via ingestão (Tabela 9). Segundo FreItAs (2002), geralmente a proporção sexual dos crisopídeos é de uma fêmea para um macho, ou seja, razãosexual de 0,5 .

Efeito dos fungicidas na fecundidade de C.exter$n a$ oriundos de larvas de primeiro ínstar contaminadas via contato ou ingestão 
Tabela 8 - Sobrevivência média (\%) de adultos de $C$. externa, 24 horas após a emergência, provenientes de larvas de primeiro ínstar tratadas com os fungicidas via contato ou ingestão. Temp.: $25 \pm 2{ }^{\circ} \mathrm{C}$; UR: $70 \pm 10 \%$ e fotofase: $12 \mathrm{~h}$.

\begin{tabular}{lcc}
\hline Tratamento & \multicolumn{2}{c}{ Forma de exposição } \\
\cline { 2 - 3 } & \multicolumn{1}{c}{ Contato } & \multicolumn{1}{c}{ Ingestão } \\
\hline Testemunha & $95,8 \pm 5,56$ a A & $91,7 \pm 5,56$ a A \\
Enxofre & $83,3 \pm 5,52$ a A & $87,5 \pm 5,55$ a A \\
Mancozebe & $94,4 \pm 5,46$ a A & $77,8 \pm 5,54$ a A \\
Oxicloreto de cobre & $87,5 \pm 5,57$ a A & $87,5 \pm 5,53$ a A \\
\hline CV $(15,4 \%)$ & $90,3 \pm 5,53$ A & $86,1 \pm 5,53$ A \\
\hline
\end{tabular}

A análise de variância não indicou diferença entre as médias $(P>0,05)$.

Tabela 9 - Razão sexual ( \pm EP) de C. externa provenientes de larvas de primeiro ínstar tratadas com os fungicidas via contato ou ingestão. Temp.: $25 \pm 2{ }^{\circ} \mathrm{C}$; UR: $70 \pm 10 \%$ e fotofase: $12 \mathrm{~h}$.

\begin{tabular}{|c|c|c|}
\hline \multirow[t]{2}{*}{ Tratamento } & \multicolumn{2}{|c|}{ Forma de exposição } \\
\hline & Contato & Ingestão \\
\hline Testemunha & $0,5 \pm 0,06$ a $A$ & $0,5 \pm 0,08$ a $A$ \\
\hline Enxofre & $0,4 \pm 0,08$ a $A$ & $0,4 \pm 0,05$ a $A$ \\
\hline Mancozebe & $0,5 \pm 0,08$ a A & $0,7 \pm 0,08$ a $A$ \\
\hline Oxicloreto de cobre & $0,6 \pm 0,07$ a A & $0,6 \pm 0,08$ a $A$ \\
\hline CV $(38,3 \%)$ & $0,5 \pm 0,07 \mathrm{~A}$ & $0,5 \pm 0,07 \mathrm{~A}$ \\
\hline
\end{tabular}

A análise de variância não indicou diferença entre as médias $(\mathrm{P}>0,05)$.

Ao longo do tempo, os modelos avaliados para ajuste das médias observadas quanto ao número e à viabilidade de ovos foram lineares e quadráticos. Dessa forma, os que proporcionaram melhor qualidade de ajuste foram $\left(R^{2} \approx 1\right)$ utilizados para regressão das médias.

Observou-sequeonúmero deovos depositados de C. externa, provenientes de larvas de primeiro ínstar tratadas com fungicidas via contato, sofreu redução aolongo do tempo. Em ordem descrescente denúmeros deovos ovipositados, foram o tratamento testemunha, oxicloreto de cobre, enxofree mancozebe(Fig. 1).

Os modelos avaliados para ajuste das médias observadas quanto ao número eà viabilidade de ovos foram lineares e quadráticos. Dessa forma, os que proporcionaram melhor qualidade de ajuste foram $\left(R^{2} \approx 1\right)$ utilizados para regressão das médias.

Para onúmero médio de ovos de C.externa, provenientes de larvas de primeiro ínstar tratadas via ingestão com enxofre, ocorreu aumento até os 9 dias e aos 12 dias houve redução até o último dia de avaliação. Com oxicloreto de cobre a oviposição foi aumentando até os 18 dias e a partir daí houve redução ao longo do tempo. Para os modelos de regressão propostos, não foi possível o seu ajuste para o tratamento quando se utilizou mancozebe via ingestão. (Fig. 2).

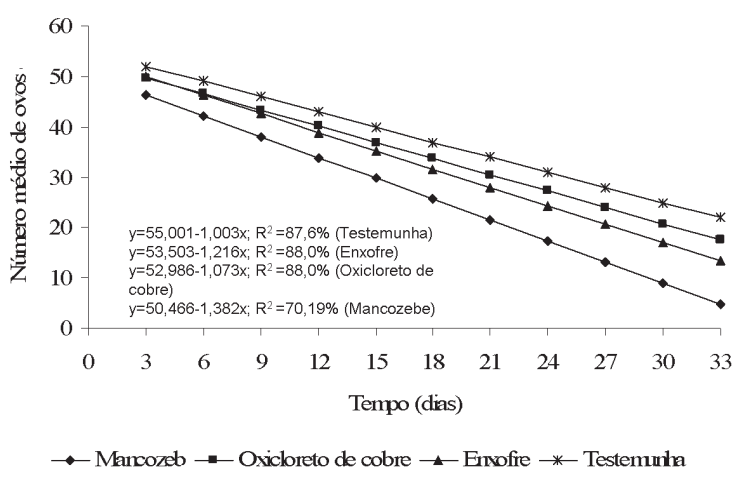

Fig. 1 - Número médio de ovos depositados de C. externa ao longo do tempo, provenientes de larvas de primeiro ínstar tratadas com fungicidas via contato. Temp.: $25 \pm 2{ }^{\circ} \mathrm{C}$; UR: $70 \pm 10 \%$ e fotofase: $12 \mathrm{~h}$.

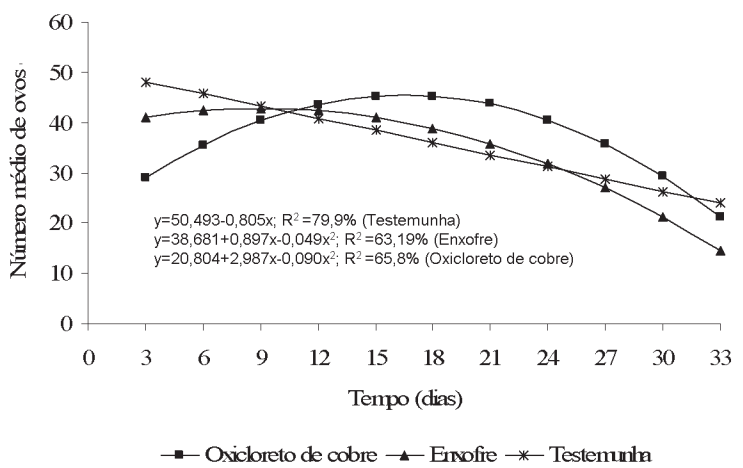

Fig. 2 - Número médio de ovos depositados por C. externa ao longo do tempo, provenientes de larvas de primeiro ínstar tratadas com fungicidas via ingestão. Temp.: $25 \pm 2^{\circ} \mathrm{C}$; UR: $70 \pm 10 \%$ e fotofase: $12 \mathrm{~h}$.

Ao longo do tempo a viabilidade dos ovos provenientes de larvas de primeiro ínstar tratadas via contato com água e mancozebe não foi significativo, mas osqueforam pulverizados com enxofre apresentaram redução até o $24^{\circ}$ dia de coleta, seguida de uma estabilização(Fig. 3). Provavelmente, ocorreu o"efeito latente", oqual, segundo CROFт (1990), éaqueleque se expressa nas fases do desenvolvimento de um organismo, subseqüente àquela que foi efetivamente exposta ao produto fitossanitário.

No tratamento com oxicloreto de cobre via contato, houve aumento da viabilidade até o $12^{\circ}$ dia e uma queda a partir desse ponto (Fig. 3). 
Ação de fungicidas utilizados na cultura do pepino sobre larvas de primeiro ínstar de Chrysoperla

externa (Hagen, 1861) (Neuroptera: Chrysopidae) e os efeitos sobre suas fases subseqüentes.

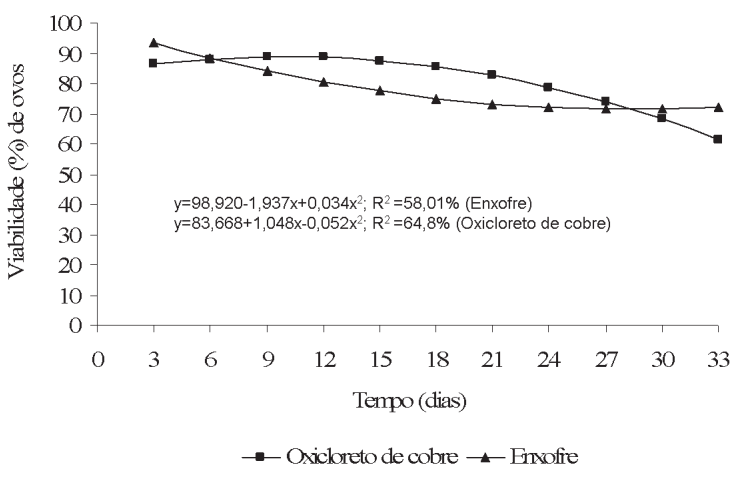

Fig. 3 - Viabilidade (\%) de ovos depositados por C. externa ao longo do tempo, provenientes de larvas de primeiro ínstar tratadas com fungicidas via contato. Temp.: $25 \pm 2{ }^{\circ} \mathrm{C}$; UR: $70 \pm 10 \%$ e fotofase: $12 \mathrm{~h}$.

Para a viabilidade dos ovos provenientes da aplicação via ingestão do enxofre, mancozebee oxicloreto de cobre, não foi possível o ajuste dos modelos de regressão propostos. No tratamento testemunha a viabilidade dos ovos ao longo do tempo não apresentou diferença a 5\% de significância pelo teste de F.

Tabela 10 - Porcentagem de mortalidade de C. externa, número médio de ovos/dia/fêmea, viabilidade dos ovos (\%), efeito total (E) e classificação de toxicidade dos fungicidas a partir de larvas de primeiro ínstar tratadas via ingestão ou contato. Temp.: $25 \pm 2^{\circ} \mathrm{C}$; UR: $70 \pm 10 \%$ e fotofase: $12 \mathrm{~h}$.

\begin{tabular}{llrllll}
\hline Tratamento & \multicolumn{6}{c}{ Exposição por contato } \\
\cline { 2 - 7 } & $\mathrm{M} \%^{1}$ & $\mathrm{Mc}^{2} \%^{2}$ & $\mathrm{R}^{\prime 3}$ & $\mathrm{R}^{\prime 4}$ & $\mathrm{E} \%^{5}$ & Classe $^{6}$ \\
\hline Testemunha & 3,3 & - & 12,3 & 90,0 & - & - \\
Enxofre & 16,1 & 13,2 & 10,5 & 78,1 & 36,0 & 2 \\
O.C & 9,2 & 6,1 & 11,2 & 81,0 & 23,1 & 1 \\
Mancozebe & 14,4 & 11,5 & 8,5 & 86,0 & 41,6 & 2 \\
\hline Tratamento & \multicolumn{6}{c}{ Exposição $^{*}$ por ingestão } \\
\cline { 2 - 7 } & $\mathrm{M} \%^{1}$ & $\mathrm{Mc}^{2}$ & $\mathrm{R}^{\prime 3}$ & $\mathrm{R}^{\prime \prime 4}$ & $\mathrm{E} \%{ }^{5}$ & Classe $^{6}$ \\
\hline Testemunha & 75 & - & 12,0 & 91,8 & - & - \\
Enxofre & 5,6 & $-2,0$ & 11,5 & 80,4 & 15,7 & 1 \\
O.C* & 13,3 & 6,3 & 12,4 & 83,5 & 12,0 & 1 \\
Mancozebe & 8,6 & 1,2 & 8,5 & 82,5 & 7,18 & 1 \\
\hline
\end{tabular}

${ }^{*} 3 \mathrm{Cu}(\mathrm{OH})_{2} \cdot \mathrm{CuCl}_{2} ;{ }^{1}$ Mortalidade (\%) acumulada na fase de desenvolvimento do predador; ${ }^{2}$ Mortalidade (\%) corrigida pela fórmula de Аввотт (1925); ${ }^{3}$ Número médio de ovos / dia/fêmea; ${ }^{4}$ Viabilidade (\%) dos ovos coletados no período de cinco semanas consecutivas; ${ }^{5}$ Efeito total (\%) dos tratamentos ao longo do desenvolvimento do predador; ${ }^{6}$ Classe de toxicidade preconizada pela IOBC (HASSAN, 1997; Sterk et al., 1999), sendo: classe 1 = inócuo ( $<$ < 30\%), classe 2 = levemente nocivo $(30 \leq \mathrm{E} \leq 79 \%)$, classe $3=$ moderadamente nocivo $(80 \leq \mathrm{E} \leq 99 \%)$ e classe $4=$ nocivo (E > 99\%). total

Classificação dos fungicidas em função do efeito

Os fungicidas enxofre e mancozebe foram enquadrados na classe $2=$ levemente nocivo $(30 \leq \mathrm{E}$ $<79 \%$ ) quando em contato e classe $1=$ inócuo (E $<30 \%$ ), quando ingerido. Para oxicloreto de cobre, a forma de exposição não influenciou na classificação toxicológica, sendo classificado na classe $1=$ inócuo $(\mathrm{E}<30 \%)$ via contato ou ingestão (Tabela 10). Resultado semelhante foi relatado por Silva et al. (2005) para esse fungicida via contato em larvas de primeiro ínstar de C. externa na cultura cafeeira.

Os fungicidas enxofre e mancozebe aplicados em larvas de primeiro ínstar apresentaram maior toxicidade via contato do que ingestão. Provavelmente, por contato houve maior penetração do produto nas larvas do crisopídeo; já via ingestão, o produto pode não ter alcançado a hemolinfa dos pulgões em nível suficiente para causar toxicidade aopredador.

\section{AGRADECIMENTOS}

À Capes pela concessão de bolsa de mestrado a Ronelza Rodrigues Dacosta, e ao Prof. Dr. Marcelo ÂngeloCirillo, do Depto. deCiências Exatas, daUFLA, pelo auxílio na análise estatística.

\section{REFERÊNCIAS}

ABBOTT, W.S. A method of computing the effectiveness of an insecticide. Journal of Economic Entomology, v.18, p.265-267, 1925.

ÁVILA, A.C. de Viroses de cucurbitáceas. Informe Agropecuário, v.8, n.85, p.52-53, 1982.

AUN, V. Aspectos da biologia de Chrysoperla externa (Hagen, 1861) (Neuroptera: Chrysopidae). 1986. 65p. Dissertação (Mestrado em Entomologia) - Escola Superior de Agricultura "Luiz de Queirós", Piracicaba, 1986.

BANZATTO, D.A.; KRONZA, S.N. Experimentação agrícola. Jaboticabal: FUNESP, 1989. 238p.

BERTI FILHO, E.; RIBEIRO, L.J.; ANTÔNIO, M.B. Crisopídeos podem estar atuando no controle da lagarta minadora dos citros. Laranja, v.96, n.1, p.12-13, 2000.

BUENO, V.H.P. Controle biológico de afídeos-praga em cultivos protegidos. Informe Agropecuário, v.26, n.225, p.9-27, 2005. 
COSTA, R. I. F.; ECOLE, C.C.; SOARES, J.J.; MACEDO, L.P.M. Duração e viabilidade das fases pré-imaginais de Chrysoperla externa (Hagen) alimentada com Aphis gossypii Glover e Sitotroga cerealella (Oliver). Acta Scientiarum, v.24, n.2, p.353-357, 2002.

CROFT, B.A. Arthropod biological control agents and pesticides. Environmental Science and Technology. New York: Wiley-Interscience, 1990. 723p.

DEGRANDE, P.E. Guia prático de controle das pragas do algodoeiro. Dourados: UFMS, 1998. 60p.

DEGRANDE, P.E.; REIS, P.R.; CARVALHO, G.A.; BELARMINO, L.C. Metodologia para inimigos naturais. In: PARRA, J.R.P.; BOTELHO, M.; CORRÊAFERREIRA, B.S.; BENTO, J.M.S. (Ed.). Controle biológico no Brasil: parasitóides e predadores. São Paulo: Manole, 2002. p.71-94.

FERREIRA, D.F. Análises estatísticas por meio do SISVAR para Windows ${ }^{\circledast}$ versão 4.0. In: REUNIÃO ANUAL DA REGIÃOBRASILEIRA DA SOCIEDADE INTERNACIONAL DE BIOMETRIA, 45., 2000, São Carlos, SP. Programas e Resumos. São Carlos: UFSCAR, 2000. p.235.

FONSECA, A.R; CARVALHO, C.F; SOUZA, B. Capacidade predatória e aspectos biológicos das fases imaturas de Chrysoperla externa (Hagen, 1861) (Neuroptera: Chrysopidae) alimentada com Schizaphis graminum (Rondani, 1852) (Hemiptera: Aphididae) em diferentes temperaturas. Ciência e Agrotecnologia, v.25, n.2, p.251263, 2001.

FREITAS, S. O uso de crisopídeos no controle biológico de pragas. In: PARRA, J.R.P.; BOTELHO, M.; CORRÊAFERREIRA, B.S.; BENTO, J.M.S. (Ed.). Controle biológico no Brasil: parasitóides e predadores. São Paulo: Manole, 2002. p.209-224. 635 p

FREITAS, S.; FERNANDES, O.A. Crisopídeos em agroecossistemas. In: Simpósio de Controle Biológico, 5., Foz do Iguaçu, PR, Brasil. Anais. Foz do Iguaçu: Conferências e Palestras, 1996. p.283-287.

HASSAN, S.A. Métodos padronizados para testes de seletividade, com ênfase em Trichogramma. In: PARRA, J.R.P.; ZUCCHI, R. (Ed.). Trichogramma e o controle biológico aplicado. Piracicaba: FEALQ, 1997. p.207-233.

JULIATTI, F.C. Manejo integrado de fungos fitopatogênicos. In: SILVA, L.H.C.P.; CAMPOS, J.R.; NOJOSA, G.B.A. (Org.). Manejo integrado de doenças: doenças e pragas em hortaliças. Lavras: UFLA, 2001. p.159-220.
MATTHEWS, G.A.; TUNSTALL, J.P. Insect pests of cotton. Cambridge: Cab International, 1994. 593p.

PESSOA, L.G.A.; SOUZA, B.; SILVA, M.G. Aspectos biológicos das fases imaturas de Chrysoperla externa (Hagen, 1861) (Neuroptera: Chrysopidae) alimentada com Aphis gossypii Glover, 1877 (Hemiptera: Aphididae) criado em quatro cultivares de algodoeiro. Arquivos do Instituto Biológico, São Paulo, v.71, n.2, p.197-202, 2004.

SANTOS, T.M. DOS; BOIÇA JÚNIOR, A.L.; SOARES, J.J. Influência dos tricomas do algodoeiro sobre os aspectos biológicos e capacidade predatória de Chrysoperla externa (Hagen) alimentada com Aphis gossypii Glover. Bragantia, v.62, n.2, p.243-254, 2003.

SAS INSTITUTE. SAS/STAT: users guide. Cary, NC, 1990.

SILVA, R.A.S.; CARVALHO, G.A.; CARVALHO, C.F.; REIS, P.R.; PEREIRA, A.M.A.R.; COSME, L.V. Toxicidade de produtos fitossanitários utilizados na cultura do cafeeiro a larvas de Chrysoperla externa (Hagen) (Neuroptera: Chrysopidae) e efeitos sobre as fases subseqüentes do desenvolvimento do predador. Neotropical Entomology, v.34, n.6, p.951959, 2005.

STERK, G.; HASSAN, S.A.; BAILLOD, M.; BAKKER, F.; BLUMEL, S.; BOGENSCHUTZ, H.; BOLLER, E.; BROMAND, B.; BRUN, J.; CALIS, J.N.M.; COREMANSPELSENEER, J.; DUSO, C.; GARRIDO, A.; GROVE, A.; HEIMBARCH, U.; HOKKANEN, H.; JACAS, J.; LEWIS, G.; MORETH, L.; POLGAR, L.; ROVERSTI, L.; SAMSOEPETERSEN, L.; SAUPHANOR, B.; SCHAUB, L.; STAUBLI, A.; TUSET, J. J.; VAINIO, A.; VAN DE VEIRE M.; VIGGIANI, G.; VINUUELA, E.; VOGT, H. Results of the seventh joint pesticide testing programme carried out by the IOBC/WPRS - Working Group "Pesticides and Beneficial Organisms". BioControl, v.44, n.1, p.99117, 1999.

VOGT, H. Untersuchungen zu nebenwirkungen von insektiziden und akariziden auf Chrysoperla carnea (Stephens) (Neuroptera: Chrysopidae). Mededelingen Rijksfaacuteit Landbouwwetenschappen te Gent, v.57, n.2b, p.559-567, 1992.

Recebido em 19/10/07

Aceito em 14/8/08 